\title{
The functional outcomes and complications of different reconstruction methods for Giant cell tumor of the distal radius: comparison of Osteoarticular allograft and three-dimensional-printed prosthesis
}

Yitian Wang ${ }^{\dagger}$, Li Min ${ }^{\dagger}$, Minxun Lu, Yong Zhou, Jie Wang, Yuqi Zhang, Xinzhu Yu, Fan Tang, Yi Luo, Hong Duan and Chongqi Tu*

\begin{abstract}
Background: En bloc excision has been increasingly used for the management of giant cell tumors (GCTs) in the distal radius. An osteoarticular allograft has been used extensively for decades, and custom-made prosthesis reconstruction has been more recently applied. We aimed to compare the clinical outcomes of the two procedures.

Methods: We retrospectively analyzed 30 patients with Campanacci III or recurrent GCTs of the distal radius for follow-up at a mean of 33.2 months. In total, 15 underwent osteoarticular allograft reconstruction (allograft group) and 15 received cementless three-dimensional (3D)-printed prosthesis reconstruction (prosthesis group) between March 18, 2013, and May 20, 2018. All patients underwent by clinical and radiological examinations, including pre- and postoperative active range of motion (ROM) of the wrist, VAS score, grip strength, degenerative change of wrist, Mayo wrist score and Musculoskeletal Tumor Society (MSTS) score. Complications were evaluated using the Henderson classification.

Results: Both groups showed significantly increased ROM, grip strength, Mayo score and MSTS score postoperatively. Furthermore, the extension, flexion, MSTS, and Mayo score were significantly higher in the prosthesis group. There was no significant difference in grip strength and VAS between the groups. In allograft group, one patient had a late infection one had resorption of allograft without allograft bone fracture. and four had wrist subluxation. All patients had degenerative changes (mean 9 months). In the prosthesis group, three patients developed wrist subluxation, three had separation of the distal radioulnar joint, and none of the patients developed wrist degeneration.
\end{abstract}

Conclusions: Our study compared the objective functional outcomes and complications of two reconstructive methods for Campanacci III or recurrent GCT in the distal radius. 3D-printed prosthesis replacement can partially preserve wrist function better than allograft reconstruction in the short-term. During the design of 3D-printed prosthesis, preoperative morphological assessment of the affected proximal row carpal is helpful to control postoperative dislocation. After allograft reconstruction, wrist degeneration, which has been demonstrated in all patients, severely influence their wrist function. Therefore, compared to allograft reconstruction, 3D-printed prosthesis reconstruction has irreplaceable advantages at early-stage application, especially in wrist function, however, further studied with a larger number of cases and longer follow-up.

Keywords: Distal radius, Giant cell tumor, Osteoarticular allograft, 3D-printed prosthesis

\footnotetext{
* Correspondence: tuchongqibone@hotmail.com

${ }^{\dagger}$ Yitian Wang and Li Min contributed equally to this work.

Department of Orthopedics, West China Hospital, Sichuan University, No. 37

Guoxuexiang, Chengdu 610041, Sichuan, People's Republic of China
}

(c) The Author(s). 2020 Open Access This article is distributed under the terms of the Creative Commons Attribution 4.0 International License (http://creativecommons.org/licenses/by/4.0/), which permits unrestricted use, distribution, and reproduction in any medium, provided you give appropriate credit to the original author(s) and the source, provide a link to the Creative Commons license, and indicate if changes were made. The Creative Commons Public Domain Dedication waiver (http://creativecommons.org/publicdomain/zero/1.0/) applies to the data made available in this article, unless otherwise stated. 


\section{Introduction}

The distal radius is the third most common location for giant cell tumor (GCT) after the distal femur and proximal tibia, and approximately $10 \%$ of GCT involve the distal radius [1,2]. Although the majority of studies do not support the theory that GCT in the distal radius are more aggressive, controversy exists on the surgical options for patients with GCT in the distal radius, as well as it's the rate of recurrence. Intralesional curettage and cement packing is the most common treatment for Campanacci I and II lesions [3, 4]. However, for Campanacci III or recurrent GCT of the distal radius, en bloc resection and reconstruction is recommended; this is associated with a lower risk of local recurrence and poorer functional outcomes than intralesional surgery [3, 5-7]. Reconstruction of the wrist joint following en bloc resection of the distal radius is challenging because of the high functional demands of the wrist, limited surrounding soft tissue, limited bone mass and the proximity of important nerves and tendons $[8,9]$. Numerous reconstructive procedures have been described including prosthetic replacement [9-11], osteoarticular allograft [12, 13], allograft fusion [14], arthrodesis using bulk autograft [1, 2], ulnar translocation [15], and nonvascularized [16] or vascularized [17] fibular graft with or without arthrodesis [18]. Although these techniques have unique advantages and inevitable complications, a gold standard for distal wrist reconstruction has not yet been established.

As a major treatment method, osteoarticular allografts have advantages, including osteoinduction, use as a biologic scaffold, and generally appropriate anatomical match for host proximal row carpel [13, 19]. However, the use of osteoarticular allografts is extremely restricted by the limited quantity and severe complications, including ankylosis, rejection, and allograft fracture [19]. As a result, several prosthetic arthroplasties have been reported in the last decade, and acceptable results of prosthesis reconstruction were demonstrated short- to mid-term $[9,20,21]$. However, potential complications included aseptic loosening caused by cement-fixation and inappropriate anatomical matching [11, 22]. Following technological advances in materialogy and manufacturing, 3-dimensional (3D) printing technology has been introduced in the field of orthopedics. Our institution reported the first study on a custom-made cementless 3D-printed prosthesis for distal radius GCTs [21]. No reports regarding the comparative study of osteoarticular allograft and prosthetic replacement has been published previously. The purpose of this study was to investigate the mid-term clinical outcomes of patients with GCT in the distal radius after these two reconstructive methods.

\section{Methods}

\section{Patients}

In total, 30 patients, who underwent en bloc resection of Campanacci III or recurrent GCT in the distal radius and allograft or prosthesis reconstruction between March 18,2013, and May 20, 2018, were enrolled in our study. The histopathologic diagnosis for each patient was obtained by needle biopsy. In order to determine the reconstructive option for each subject, the surgical indication was based on patient's preference. The patients, who selected biological reconstruction and rejected arthrodesis using autograft and/or ulnar translocation, underwent osteoarticular allograft. Whereas, patients, who selected endoprosthetic reconstruction and rejected arthrodesis using autograft and/or ulnar translocation underwent 3D-printed prosthesis replacement. We excluded patients with metastasis and those who had any surgical procedure unrelated for Campanacci III or recurrent GCT in the distal radius. According to the reconstructive methods, we considered a consecutive series in our institution with GCTs of the distal radius treated with osteoarticular allograft (allograft group) and 3D-printed prosthesis (prosthesis group). Preoperative assessments included radiographs of the bilateral forearm and wrist, computed tomography (CT) scan of the chest, bilateral forearm and wrist, magnetic resonance imaging (MRI) of the affected side and an optional total body bone scan. All patients were evaluated for pain according to a 10-cm VAS score, range of motion (ROM) recorded using a goniometer, grip strength of bilateral wrist joint, Mayo wrist score [23] and Musculoskeletal Tumor Rating Scale (MSTS) [24] of the wrist, preoperatively and postoperatively. All patients were assessed every 3 months during the first year of follow-up and every 6 months thereafter with a physical examination, VAS, functional evaluation of the wrist, radiographs of the wrist and chest. The degenerative changes of the wrist were evaluated radiographically according to Knirk and Jupiter scale in both groups [25]. This study was performed according to the principles embodied in the Declaration of Helsinki and the Institutional Review Board of Sichuan University West China Hospital. Written informed consent was obtained from all patients when they began treatment for osteoarticular allograft or 3D-printed prosthesis.

\section{Allograft preparation and prosthesis design}

In the allograft group, to obtain a reconstruction as anatomical as possible, the isometric $\mathrm{x}$-rays of the bilateral side and a 3D-CT scan were taken. Fresh-frozen allografts were supplied by the bone-bank facility (West China Hospital, Chengdu, Sichuan) without soft tissue.

In the prosthesis group, all prostheses were custommade for each patient by our team and produced 
(Chunli, Beijing, People's Republic of China). Based on our previous study [21] and experience, the design was modified and improved with the help of Mimics V17.0 software (Materialise Corp., Leuven, Belgium). The main components of the 3D-printed prosthesis were an ultrahigh-molecular-weight polyethylene (Orthoplastics Ltd., Lancashire, UK), repairing pores for soft tissue reconstruction, shaft and stem coated with hydroxyapatite (titanium alloy) (Fig. 1). All prostheses were printed by electron beam melting technology (ARCAM Q10, Mölndal, Sweden). It took 2 or 4 weeks to manufacture the prosthesis, during which time the patients were treated with NSAIDs if necessary.

\section{Surgical technique and postoperative management}

Patients were submitted to general anesthesia. The tumor was resected en bloc through a dorsal approach including the previous biopsy and operating incision. Soft tissue dissection, including the wrist ligaments, capsule, triangular fibrocartilage complex (TFCC), biopsy track and hematoma, was dependent on the tumor border. A step-cut osteotomy was performed with a safe margin ( $1.5 \mathrm{~cm}$ from the tumor border) according to $\mathrm{X}$ rays and MRI. In the allograft group, an appropriate locking compression plate (LCP) was fixed to the allograft bone and the remaining radius to obtain initial stability and avoid rotation of the distal radius Allograft bone was fixed with a suitable LCP, Wego, Shandong, People's Republic of China) to bridge the allograft and the remaining radius [13]. In the prosthesis group, stable fixation between the prosthesis and the reamed radius canal was enhanced by press-fitting the distal stem. The remaining dorsal and/or palmar ligaments, joint capsule and TFCC were sutured to the allograft bone or repairing pores of the prosthesis.

Based on the reserved soft tissue, an above-elbow cast was administered to patients with massive resection.

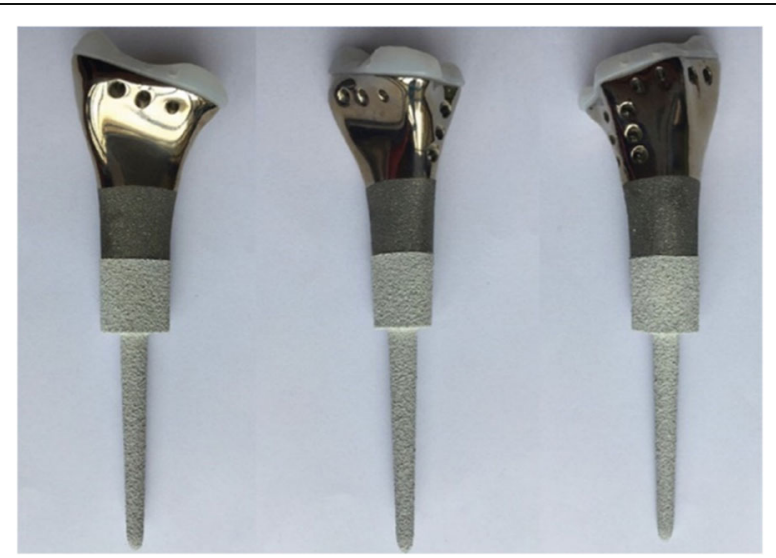

Fig. 1 Prosthesis is composed of polyethylene, repairing pores, shaft and stem coated with hydroxyapatite
After a 4-week immobilization, active wrist exercises were acceptable.

\section{Statistical analysis}

Survival data were compiled using Kaplan-Meier analysis. Prosthesis survivorship was determined for implants using revision or removal of the components for any reason as an end point, according to Henderson et al. [26]. No complication survivorship was defined for patients without wrist pain, degeneration of the wrist, subluxation, and separation of the distal radioulnar joint at the last follow-up.

The normality of the continuous data was verified by the Shapiro-Wilk test. Normally and abnormally distributed parameters were assessed by the independent sample t-test and the Mann-Whitney $U$ test, respectively. A $P$-value of $<0.05$ was determined to be statistically significant. Comparisons were conducted between the allograft and prosthesis group by log-rank test. Data analyses were performed using SPSS 20.0 software (IBM Corporation, Armonk, NY, USA).

\section{Results}

\section{Patient characteristics}

In total, 30 consecutive patients were enrolled from March 18, 2013 to May 20, 2018. All pathology materials were confirmed at West China Hospital. The clinical characteristics of the two groups and their comparison are presented in Table 1. Patients of the two treatment groups had no significant difference in gender, age, and follow-up time.

\section{Functional outcomes}

There was no significant difference between the two groups in preoperative functional outcomes. In the allograft group, there was a significant increase in ROM postoperatively, with exception of flexion. The mean postoperative ROM of the wrist, was $38.3^{\circ}$ active extension (range, $25^{\circ} 65^{\circ}, P<0.01$ ), $26.3^{\circ}$ flexion (range, $10^{\circ}-50^{\circ}, P=0.65$ ), $52.0^{\circ}$ pronation (range, $30^{\circ}$ $65^{\circ}, P=0.04$ ), and $55.0^{\circ}$ supination (range, $40^{\circ}-80^{\circ}, P=$ 0.03). The MSTS wrist score and Mayo wrist score were significantly increased postoperatively, averaging $71.2 \%$ (57.1-82.9\%, $\mathrm{P}=0.03)$ and $65.0(55-75, P<0.01)$ respectively. Postoperative grip strength was $54.7 \%$ (range, $42.5-70.3 \%$ ) of the normal contralateral hand compared to $29.7 \%$ (range, $15.9-38.3 \%$ ) preoperatively, with a significant increase $(\mathrm{P}<0.01)$. The VAS score was 5.5 (range, 4-7) preoperatively and 1.2 (range, $0-3$ ) postoperatively with significant difference $(P=0.05)$ (Table 2$)$.

In the prosthesis group, with regards to all aspects of the ROM, there were significant differences between the pre- and post-operative measurements. After prosthesis reconstruction there was a $61.7^{\circ}$ active extension (range, 
Table 1 Demographic and radiographic characteristics of the two treatment groups

\begin{tabular}{|c|c|c|c|c|c|c|c|}
\hline \multirow[t]{2}{*}{ Characteristic } & \multicolumn{3}{|c|}{ Osteoarticular allograft group } & \multicolumn{3}{|c|}{ 3D-printed prosthesis group } & \multirow{2}{*}{$\begin{array}{l}p^{-} \\
\text {value }\end{array}$} \\
\hline & Mean & SD & Range & Mean & SD & Range & \\
\hline Number of patients & 15 & - & - & 15 & - & - & - \\
\hline Male/female & $8 / 7$ & - & - & $6 / 9$ & - & - & 0.50 \\
\hline Age (years) & 37.3 & 12.1 & $24-63$ & 38.0 & 10.0 & $21-56$ & 0.87 \\
\hline Side (right/left) & $7 / 8$ & - & - & $8 / 7$ & - & - & 0.67 \\
\hline Primary/Recurrence & $11 / 4$ & - & - & $10 / 5$ & - & - & 0.7 \\
\hline Length of resection (cm) & 8.0 & 1.0 & $7-10$ & 5.4 & 1.7 & $3.5-9$ & $<0.001$ \\
\hline Follow-up (months) & 34.4 & 16.8 & $10.7-64.4$ & 31.4 & 11.8 & $13.7-48.2$ & 0.52 \\
\hline
\end{tabular}

$20^{\circ}-85^{\circ}, P<0.01$ ), $45.0^{\circ}$ flexion (range, $20^{\circ}-80^{\circ}, P=$ $0.04), 54.7^{\circ}$ pronation (range, $30^{\circ}-80^{\circ}, P<0.01$ ), and $60.0^{\circ}$ supination (range, $25^{\circ}-85^{\circ}, \mathrm{P}<0.01$ ) (Fig. 2). With respect to the MSTS score of the wrist and the Mayo wrist score, there was a significant increase after the operation of $81.7 \%(60-94.3 \%, P<0.01)$ and $71.0(40-85$, $\mathrm{P}<0.01)$ on average, respectively. There were significant differences between the pre- and post-operatively in grip strength. There were $33.2 \%$ (range, $12.8-62.7 \%, P<0.01$ ) and $64.4 \%$ (range, $31.9-100 \%, P<0.01$ ) respectively. Furthermore, there was a significant difference in VAS score, which was 5.5 (range, 4-7) preoperatively and 1.3 (range, $0-4)$ postoperatively $(\mathrm{P}<0.01)$. (Table 3 ).

With respect to the postoperative functional outcomes, the extension (38.3 vs 61.6, $\mathrm{P}<0.01$ ), flexion (26.3 vs 45.0, $P=0.02)$, grip strength $(54.7$ vs $64.4, P=0.03)$, MSTS score $(71.2$ vs $81.7, P=0.01)$, and Mayo score (65.0 vs $71.0, P=0.01$ ) were significantly higher in the prosthesis group. There was no significant difference in supination, pronation, and VAS score between the two groups (Table 4).

With regards to the variations of functional outcomes before and after surgery, although the prosthesis group showed an improvement in of ROM in the extension, flexion pronation and supination, only the extension (8.7 vs $29.7, P<0.01)$ and flexion $(1.3$ vs $12.0, P=0.020)$ were statistically significant. There was a significant difference in the variation of the Mayo wrist score (47.3 vs 51.7 , $P=0.03)$ and the MSTS score $(17.1 \%$ vs $28.6 \%, \mathrm{P}<0.01)$ in two groups. There was no significant difference between the allograft and prosthesis groups in terms of grip strength $(25.1 \%$ vs $31.2 \%, P=0.25)$ and VAS score (4.3 vs $4.2, P=0.87$ ) (Table 4 ).

With regards to the variations of satisfaction before and after surgery, there was no significant difference in the variation of satisfaction in the Mayo wrist score (20.9 vs $21.6, P=0.726$ ) between the two groups. In addition, there was a significant increase in the variation of emotional acceptance in the MSTS score (4.1 vs 1.4, $P<0.01)$ in the prosthesis group. There was a significantly lower pain reported in the prosthesis group with both the Mayo (25.00 vs 21.88, $\mathrm{P}<0.01)$ and MSTS $(5.00$ vs $4.38, P=0.02)$ scores.

\section{Complications}

In the allograft group, all patients were alive, of the 15 patients, only one had a late infection (50 months after surgery), which was caused by plate exposure (type 1B), resulting in debridement and removal of the plate. Four patients had wrist subluxation (type 1A) that occurred 2, 3,6 and 36 months after surgery. At the lastest followup, all patients had degenerative changes (three had grade 2, fourteen had grade 3, mean, 9 months; range 312 months), according to the Knirk and Jupiter scale [25]. One patient had resorption of the allograft (type 2B) without allograft bone fracture. None of the included patients had structural failures, soft-tissue failures, nonunion, metastasis, or pain.

In the prosthesis group, none of the patients died; of 15 patients, three patients developed wrist subluxation (type 1A) that occurred within 1 month after surgery. Three patients had separation of the distal radioulnar joint; two of the three patients which occurred in 1 month after surgery, while the other developed within 7 months of the surgery. None of the included patients had structural failures, soft-tissue failures, aseptic loosening, infection, pain, or degenerative changes because of the surgery. There was no significant difference between the allograft and prosthesis group with regards to complications according to the Henderson classification.

There was no significant difference between the allograft and prosthesis group in terms of implant survival $(P=0.98)$ (Fig. 3$)$, and the median survival time was not reached in either of the groups. Finally, no patients had died by the time of the last follow-up.

\section{Discussion}

Campanacci III and/or recurrent GCT in the distal radius are characterized by strong invasion and a high recurrence rate. The primary goal of treatment is an oncologic cure. and further functional satisfaction is intensely demanded. The present study is the first to 


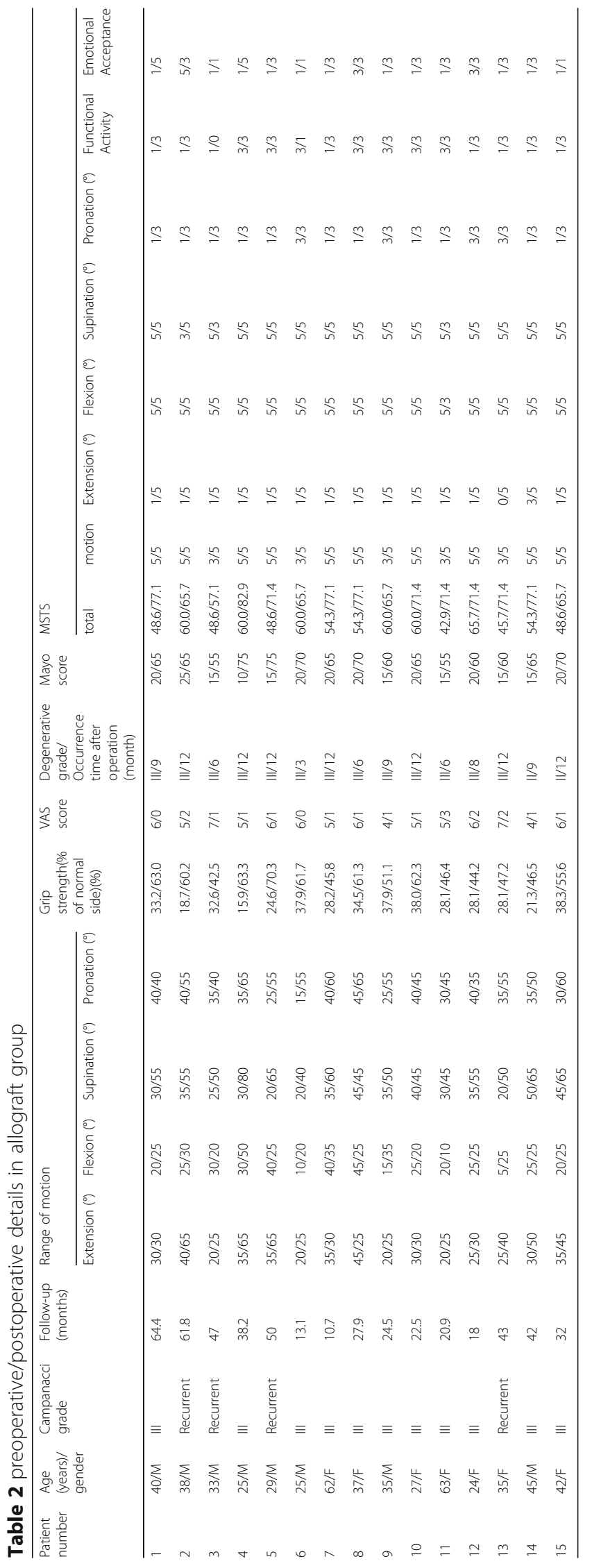




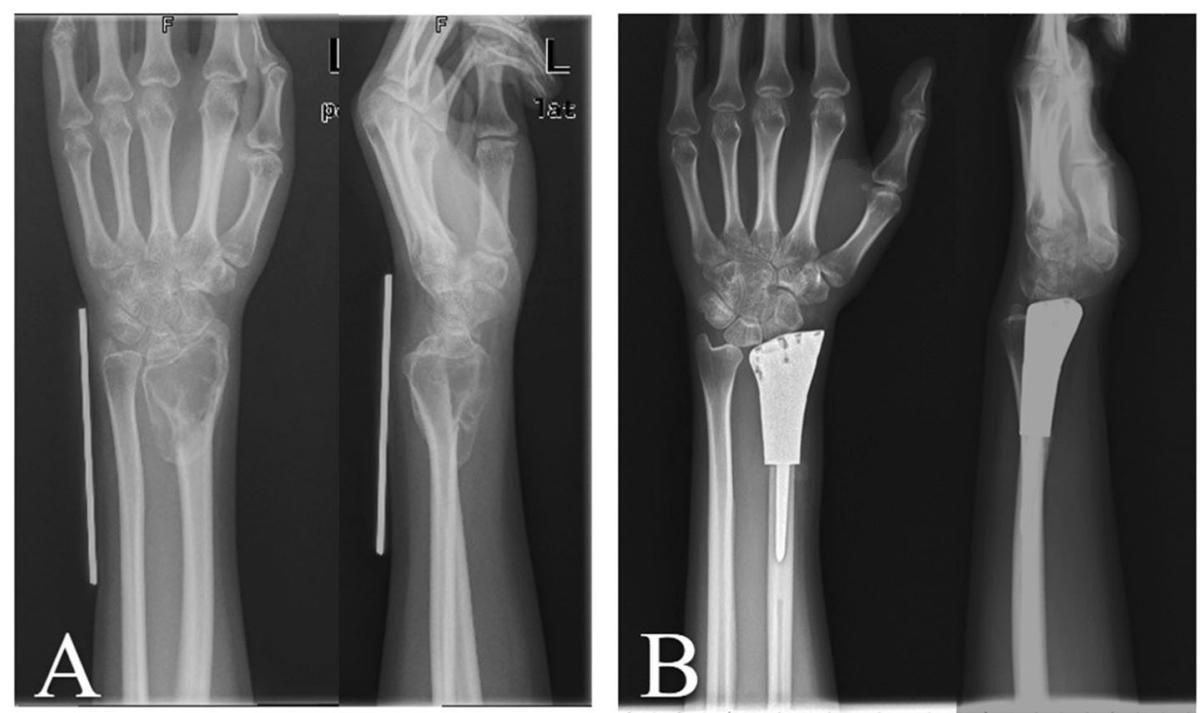

Fig. 2 a: The Campanacci III GCT of left distal radius was diagnosed; $\mathbf{b}: 10$ months after surgery

comparing allograft and prosthesis reconstruction for the treatment of GCTs in the distal radius. To highlight differences between the 3D-printed prosthesis and allograft reconstruction, the comparison was performed with regards to functional outcomes and complications. With respect to functional outcome, the MSTS and Mayo score were evaluated; in general, the prosthetic group had a significantly higher scores when compared to the variation of before and after surgery $(17.1 \%$ vs $28.6 \%, P<0.01$ and 47.3 vs $51.7, P=0.03$ ). In addition, the prosthetic group had a significantly higher score in both MSTS and Mayo, compared to the postoperative evaluation (Table 4).

\section{Comparison of range of motion (ROM)}

For the variation of ROM in the Mayo score, there was a significantly higher score in the prosthesis group compared to the allograft group (4.0 vs $6.4, P=0.04)$. There was no significant difference between groups with regards to the variation of ROM in the MSTS score (0.67 vs $0.60, P=0.84$ ). This discrepancy in ROM between the Mayo and MSTS scores may be partially explained by the fact that ROM is given a weighting of $25 \%$ in the Mayo score compared to $14 \%$ in the MSTS system. In addition, most patients received full marks in the MSTS system because the ROM was more than 120 $\circ$, and included extension, flexion, supination, pronation, and radial and ulnar deviation. However, the ROM score is valued by a percentage of the contralateral side in the Mayo system, which rarely receives gets full marks.

In previous studies, custom-made cemented prosthesis reconstruction obtained reasonable ROM, with different types, including distal radial prosthesis [9, 11, 20], and total wrist joint prosthesis prothesis [22, 27, 28]. For our
3D-printed uncemented prosthesis, not only the individual and precise design, but also the "press-fit" fixation make surgery easy and result in considerable functional outcomes [21]. Our 3D-printed prosthesis has three main advantages. First, a thick and suitable polyethylene liner is made according to the contralateral side; second, the reserved bone crest of the distal radius on the shaft ensure appropriate implantation without any rotation; and third, seven or eight pores, on the distal prosthetic edge, provide a sufficient area for soft tissue reconstruction. For the allograft group, all patients developed grade 2 or 3 degeneration of the wrist joint (Fig. 4), and the median degeneration-time was 9 months (95\% CI: 8.039.97) (Fig. 5). There might be an explanation in that creeping substitution, the process through which the allograft is gradually replaced by living bone [29], goes to tide mark under dead articular cartilage, therefore there is a risk of subchondral collapse [30]. With respect to forearm rotation, the distal radioulnar joint (DRUJ) plays a critical role. We reveal that four patients developed separation of the DRUJ (Fig. 6) in prosthetic reconstruction. Based on the tumor border, most structures of the triangular fibrocartilage complex (TFCC) were not preserved in the four patients; therefore, there was a tendency for separation of the DRUJ. With respect to the stabilizing structures of the DRUJ, which includes the TFCC, surrounding ligament, tendon, muscle, interosseous membrane, the bone itself, and the capsule [31]. The TFCC, containing superficial and deep fibers, is the main stabilizer of the DRUJ [32]. Many studies concluded that the dorsal superficial fibers tighten in pronation, as do the deep palmar fibers and vice versa [31]. Therefore, we speculate that the relative decrease in pronation and supination is associated with insufficient reconstruction of 


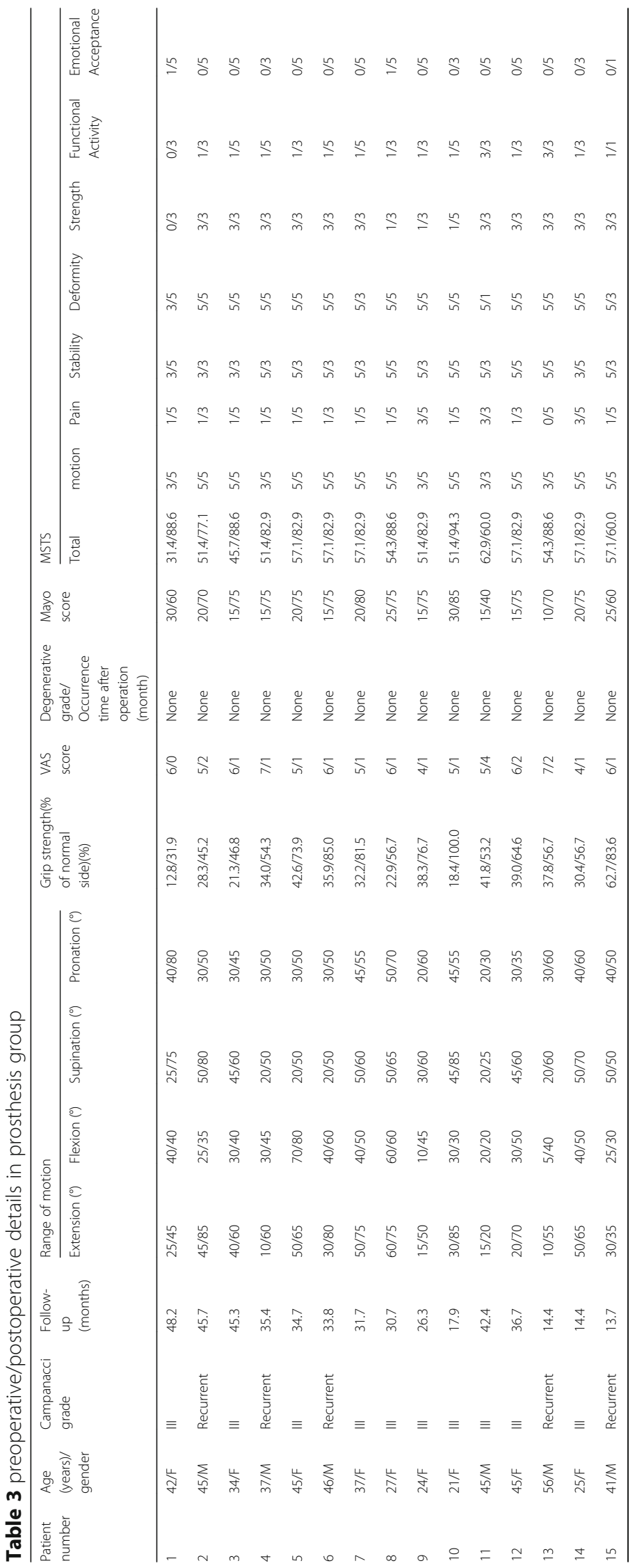


Table 4 Statistical comparison of clinical results between the two treatment groups

\begin{tabular}{|c|c|c|c|}
\hline Measure & Osteoarticular allograft group $(N=15)$ & 3D-printed prosthesis group $(N=15)$ & $\begin{array}{l}\text { p-value } \\
\text { allograft vs prosthesis }\end{array}$ \\
\hline \multicolumn{4}{|l|}{ Postoperative } \\
\hline Extension $\left({ }^{\circ}\right)$ & 38.3 (range 25 65) & 61.7(range 20 85) & $<0.01$ \\
\hline Flexion $\left(^{\circ}\right)$ & 26.3 (range 10 50) & 45.0 (range 20 80) & 0.02 \\
\hline Supination $\left({ }^{\circ}\right)$ & 55.0 (range 40 80) & 60.0(range $25 \sim 85$ ) & 0.187 \\
\hline Pronation $\left({ }^{\circ}\right)$ & 52.0 (range 30 65) & 54.7 (range 30 80) & 0.683 \\
\hline Mayo score & 65.0 (range 55 75) & $71.0(40 \sim 85)$ & 0.013 \\
\hline MSTS score & 71.2 (range $57.1 \sim 82.9$ ) & 81.7 (range 60 94.3) & 0.01 \\
\hline VAS score & 1.2 (range $0 \sim 3$ ) & 1.3 (range $0 \sim 4$ ) & 0.806 \\
\hline Grip strength (\% of normal side) (\%) & 54.7 (range $42.5 \sim 70.3$ ) & 64.4 (range 31.9 100) & 0.03 \\
\hline \multicolumn{4}{|l|}{ The variations before and after surgery } \\
\hline Extension $\left(^{\circ}\right)$ & 8.7 (range - 20 30) & 29.7 (range 5 55) & $<0.01$ \\
\hline Flexion $\left(^{\circ}\right)$ & 1.3 (rang -20 20) & 12.0 (range 0 35) & 0.02 \\
\hline Supination $\left(^{\circ}\right)$ & 22.0 (range $0 \sim 50$ ) & 24.0 (range $0 \sim 50$ ) & 0.624 \\
\hline Pronation $\left(^{\circ}\right)$ & 18.0 (range $-5 \sim 40)$ & 20.7 (range 10 40) & 0.635 \\
\hline Mayo score & 47.3 (rang 40 65) & 51.7 (range 25 60) & 0.03 \\
\hline MSTS score & 17.1 (range 5.7 28.6) & 28.6 (range $-2.9 \sim 57.1$ ) & $<0.01$ \\
\hline VAS score & 4.3 (range 2 6) & 4.2 (range 1 6) & 0.870 \\
\hline Grip strength (\% of normal side) (\%) & 25.1 (range 10.0 47.4) & 31.2 (range 11.4 81.6) & 0.250 \\
\hline
\end{tabular}

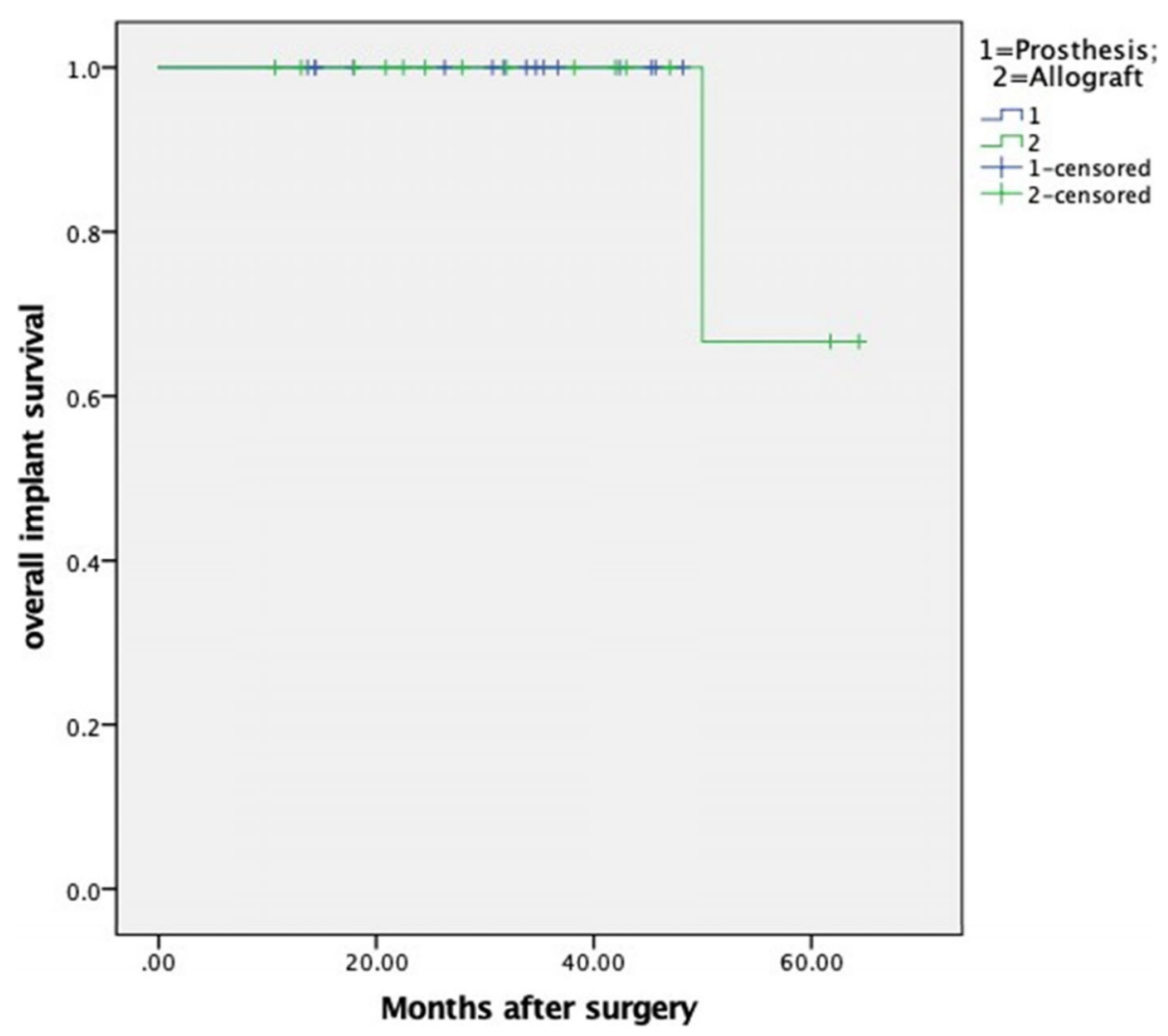

Fig. 3 The Kaplan-Meier curve shows the overall implant survival for allograft and prosthesis group, respectively 

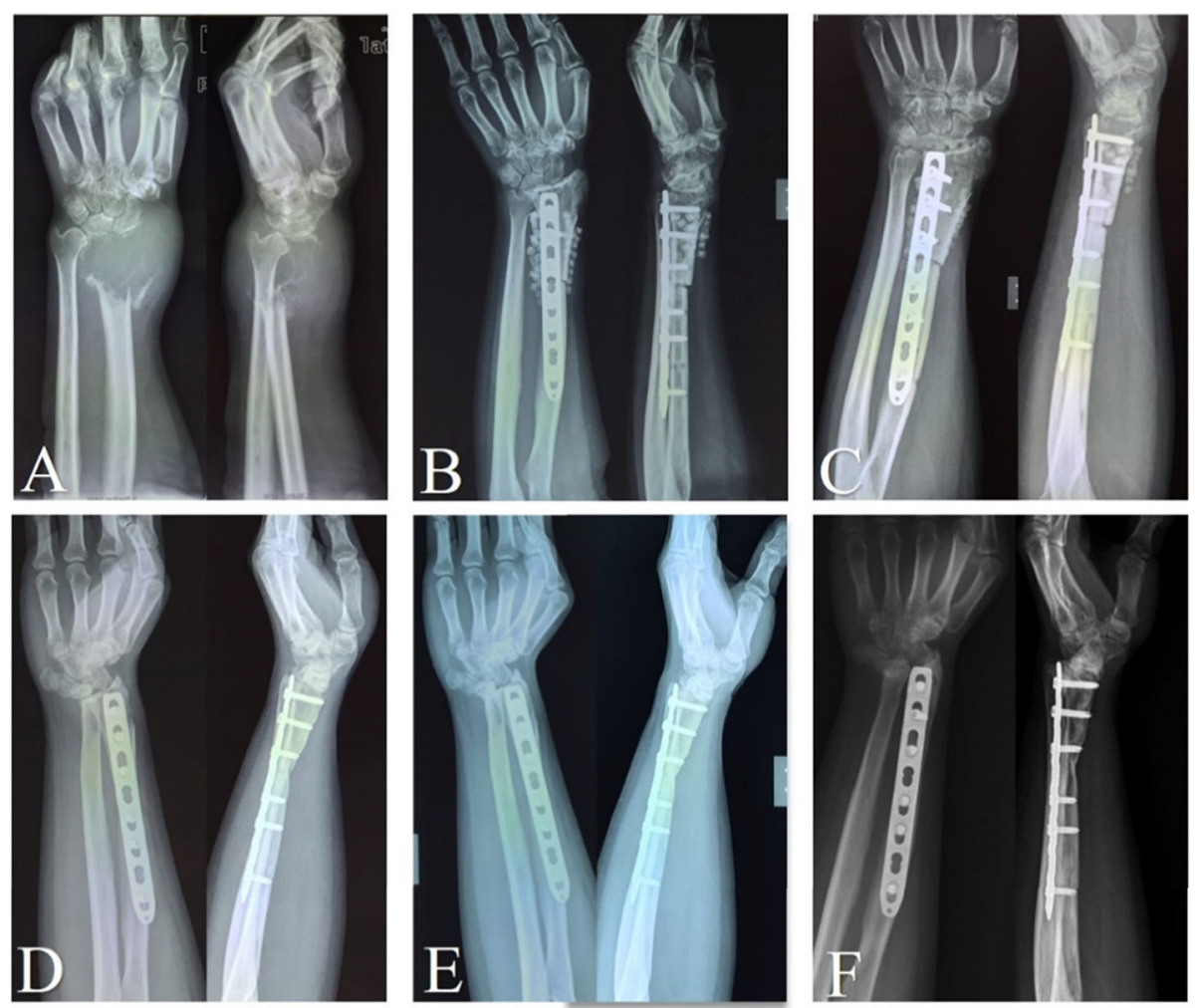

Fig. 4 The serial X-rays show the nature of radiological degeneration with allograft reconstruction. A: before surgery; B: 2 days after surgery; C: 2 months after surgery; D: 10 months after surgery; E: 24 months after surgery; F: 54 months after surgery

the TFCC. When soft tissue reconstruction is achieved, we suggest that the retained fibers of the TFCC should be precisely reconstructed by suturing. No separation of the DRUJ was detected in allograft patients, because of selection bias and longer immobilization postoperatively.

\section{Comparison of pain}

Compared to the postoperative pain, there was a significantly lower level of pain in the prosthesis group in terms of both Mayo (22.3 vs 15.3, $P<0.01)$ and MSTS (5.30 vs $3.13, P=0.04$ ) score. However, the postoperative pain score was not significantly different with VAS evaluation (1.2 vs $1.3, P=0.985)$. Although the pain was fairly decreased postoperatively in both reconstruction methods, the patients in the prosthesis group complained less of pain compared to those in the allograft group. We speculate that the anatomical and precise design increases the matching of joint compatibility and improved comfort for patients. For prosthesis reconstruction, Zhang et al. reported that only 1 patient complained of moderate pain in a total of 11 patients [9], Wang et al. reported that no patients suffered pain with activity in a total of 10 patients [20]. Secondly, allograft reconstruction has shown a high rate of joint degeneration, which increased the level of pain and decreased the ROM. Rabitsch et al. reported $100 \%$ joint degeneration in 4 patients [33], while Duan et al. reported $100 \%$ joint degeneration in 15 patients [13].

\section{Comparison of satisfaction}

With respect to postoperative satisfaction in terms of MSTS score, there was a significantly higher satisfaction in the prosthesis group compared to allograft group (2.88 vs $4.25, P<0.01)$. Nevertheless, there was no significant difference between groups 22.19 vs $23.44, P=$ 0.30 ) with regards to the Mayo score. This discrepancy may be partially explained by the difference in the weighting of satisfaction in the Mayo and MSTS scores. Although the discrepancy was found in the Mayo and MSTS scores evaluating functional outcomes, a comprehensive comparison was performed between groups using the Mayo and MSTS score. Overall, the prosthetic reconstruction had a better functional outcome, compared to the allograft reconstruction.

\section{Comparison of complications with Henderson classification}

With respect to complications, the main potential problems for the allograft, including nonunion, allograft fracture, wrist osteoarthritis, slow incorporation of the allograft, and rejection, have been reported after en bloc resection (Table 5). Indeed, Bus et al's compared the 


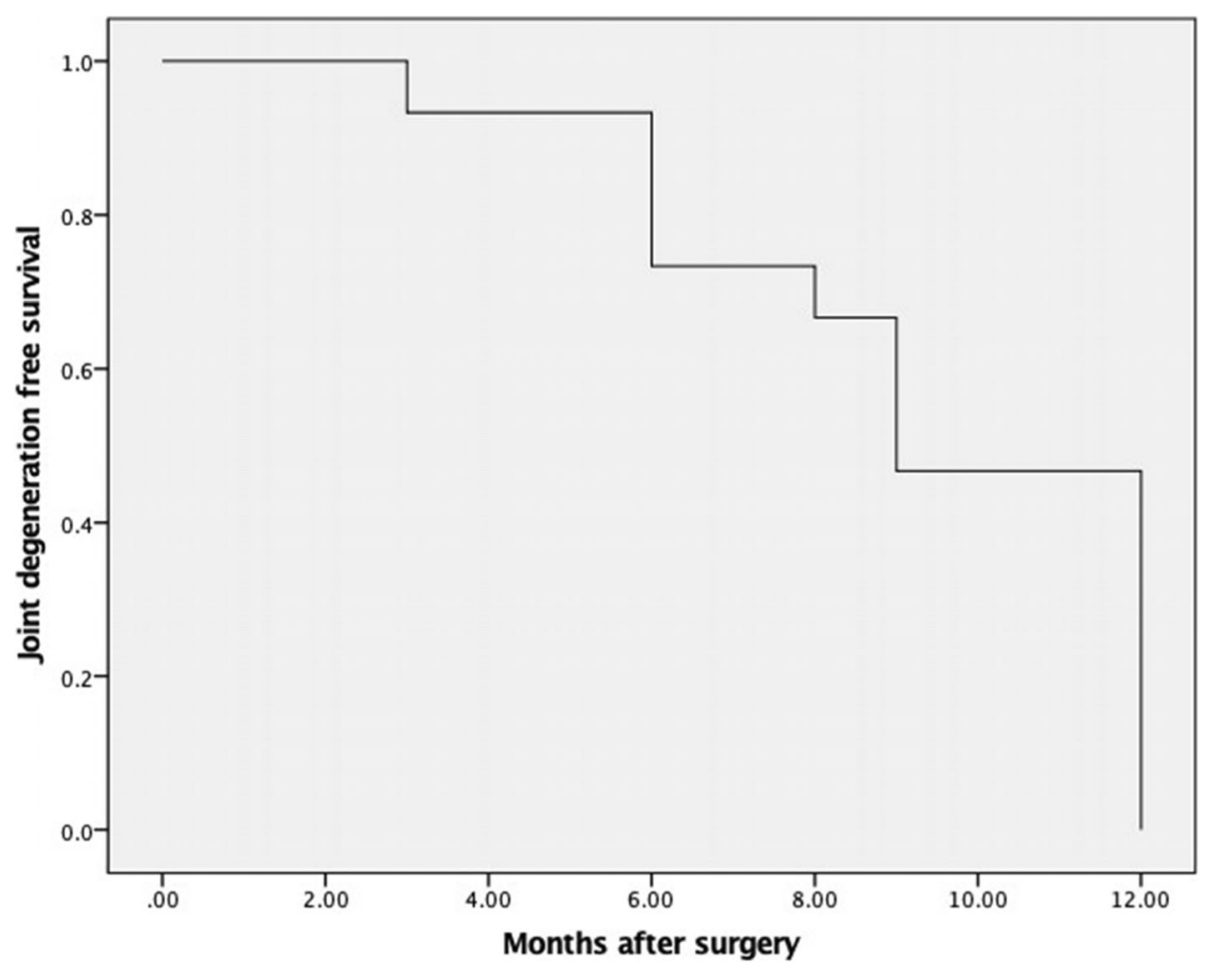

Fig. 5 The Kaplan-Meier curves show that the median degeneration-time of wrist was 9 months (95\% Cl: 8.03-9.97), in all patients with allograft reconstruction after en bloc excision
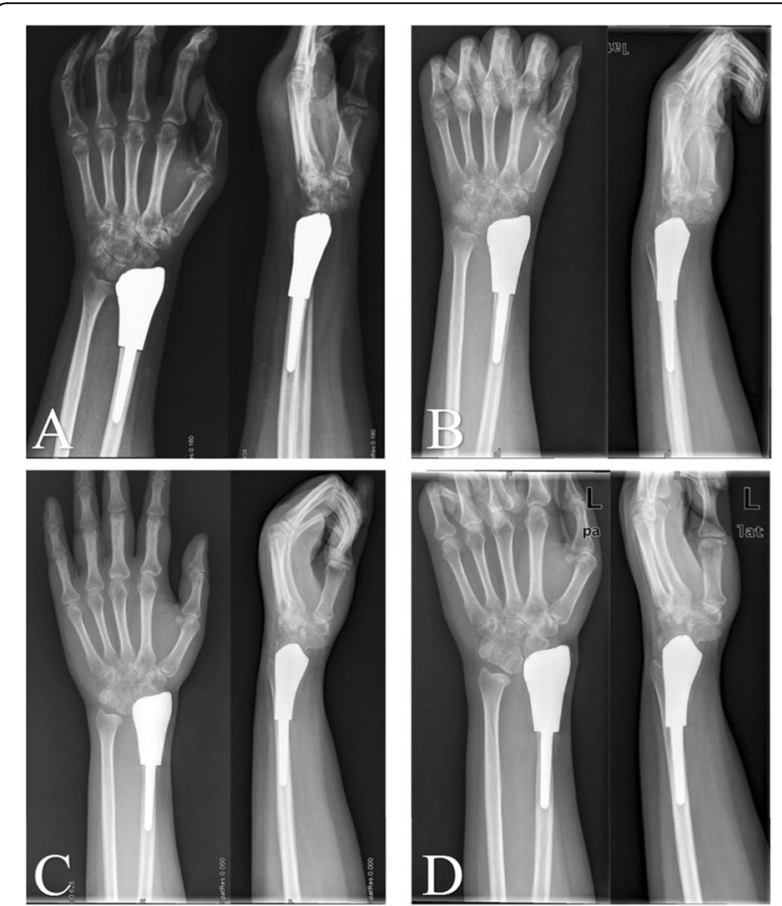

Fig. 6 The serial X-rays show the separation of left DRUJ after prosthetic reconstruction. A: 2 days after surgery; B: 1 month after surgery; C: 12 months after surgery; D: 42 months after surgery complication rates of allograft reconstruction between different sites, and demonstrated that the distal radius showed a significantly lower risk in structural failure and infection compared to the proximal tibia, distal femur, and proximal humerus [38]. Furthermore, the LCP makes reconstructions easy and may be expected to result in fewer complications [13]. As a result, previous authors have suggested that if an intercalary allograft survives the critical 3 to 4 years, it is likely to last for many years [39]. In our study, four patients had palmer subluxation, three of which developed palmer subluxation within the 6 months after surgery. There are three potential reasons for this finding: firstly, the strength of the flexor is greater than that of the extensor [31], developing the tendency of palmer dislocation; secondly, all the patients underwent a dorsal approach, protecting most of the stabilizing structures in the palmar; and thirdly, without the pores in the prosthesis, the retained soft tissue suturing is tedious and unreliable. One patient progressively acquired palmer subluxation in the third year after operation (Fig. 7). According to the radiograph, we speculate that the subluxation was subordinate to the carpal degeneration.

The main potential complications associated with prosthesis are subluxation, aseptic loosening, infection, soft-tissue failure and fracture of the prosthesis $[9,11$, 20, 22, 40] (Table 6). In the present study, three patients 


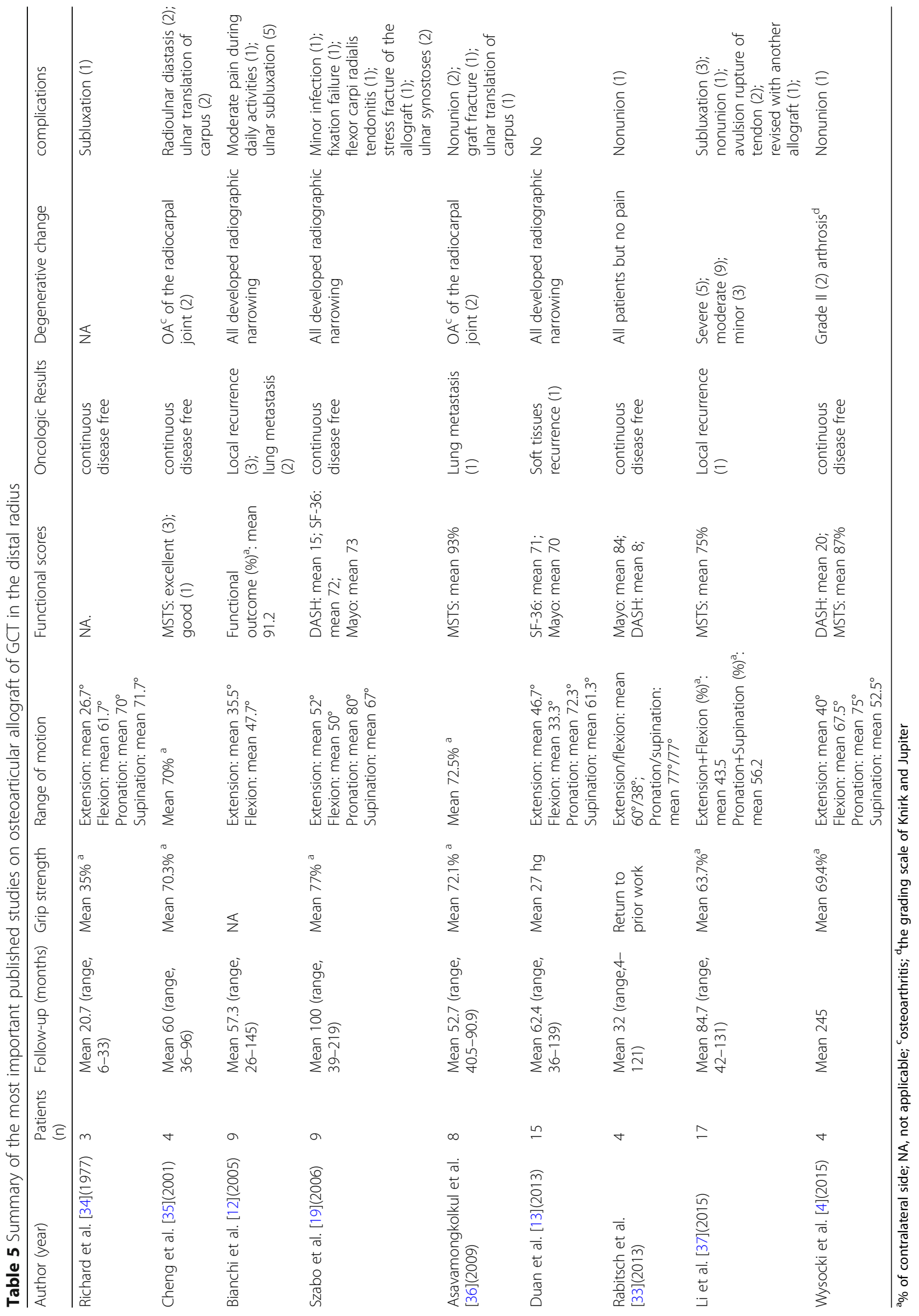




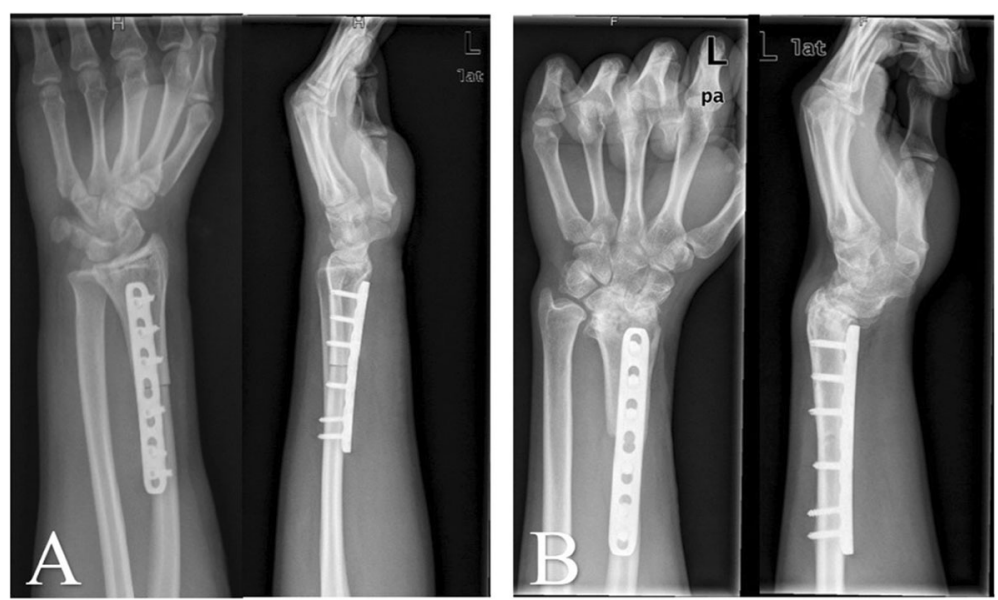

Fig. 7 The left palmer subluxation was found in the third year after allograft reconstruction. A: 2 days after surgery; B: 36 months after surgery

developed palmar subluxation that occurred within 1 month of surgery (Fig. 8). In theory, mirroring of the contralateral normal distal radius is the best anatomical match. Accounting for distal radial volar palmar tilt 11$12^{\circ}[31]$, the tendency, for volar subluxation for the carpus to slide off the distal radius, is inevitable. However, soft-tissue tension is affected by the expansive growth of the lesion, especially in Campanacci III or recurrent GCTs of bones [42], and the degeneration of proximal row carpal is generally detected in our elderly patients or those with recurring disease. Hence, total mirroring of the contralateral side may be misleading in this respect, and we propose that the degeneration of the proximal row carpal should be religiously considered. Additionally, it is advisable to sequentially reconstruct retained soft tissue for appropriate soft tissue tension [21]. In addition, radius lengthening combined with folding-plasty of soft-tissue reconstruction is an effective method.

Most studies report wrist joint degeneration after allograft reconstruction (Table 5), while wrist joint degeneration was rarely detected using the prosthesis method. Duan et al. reported that degeneration was revealed in a mean of 4 months postoperatively [13], while we found degeneration with a mean of 9 months. We speculate that the wrist joint degeneration secondary to allograft reconstruction develops in the first year postoperatively. With respect to the comparison of wrist subluxation, although there was no significant difference between the allograft (4 patients) and prosthesis (3 patients) groups, different mechanisms were found in the two groups. For allograft reconstruction, subluxation was subordinate to the gradual carpal degeneration, while subluxation was mostly dependent on the prosthetic design and retained soft tissue.

This study presents several limitations, mainly due to the nature of the disease. Firstly, our study was retrospective with a small size (15 patients in each group). As such, our small sample size may be expected to result in low statistical power. Secondly, the follow-up time was significantly different in the two groups, and the follow-up time is insufficient to make conclusions on the long-term implications of the result. Thirdly, no patient was administered denosumab preoperatively. The efficacy of denosumab has been demonstrated in patients with unresectable or recurrent GCT of bone, according to the NCCN guideline and previous studies [43]. However, denosumab did not show any effect on reducing the recurrence rate [44], and complications such as sarcomatous transformation should be considered [45]. Fourthly, our findings are only based on the respective data from our institution, this implies a study selection bias that must be acknowledged, and which might only reflect surgeon or patient preference. As such, this may have had a substantial impact on our observations. Finally, we did not have sufficient reconstruction types such as autograft fibula grafts, for arthrodesis or osteoarticular reconstructions nor did we look at vascularized fibular grafts; as a result, our ability to state that arthrodesis is a superior reconstruction method is limited and we can only show that the results in our patients provided them with reasonable function.

\section{Conclusions}

This is the first study comparing the objective functional outcomes and complications of two reconstructive methods for the Campanacci III or recurrent GCTs in the distal radius. Despite including subluxation cases, 3D-printed prosthesis replacement at short-term followup can partially preserve better wrist function than osteoarticular allograft reconstruction at short-term and even median-term follow-up. During the 3D-printed prosthesis design, preoperative morphological assessment of the affected proximal row carpal is helpful to 


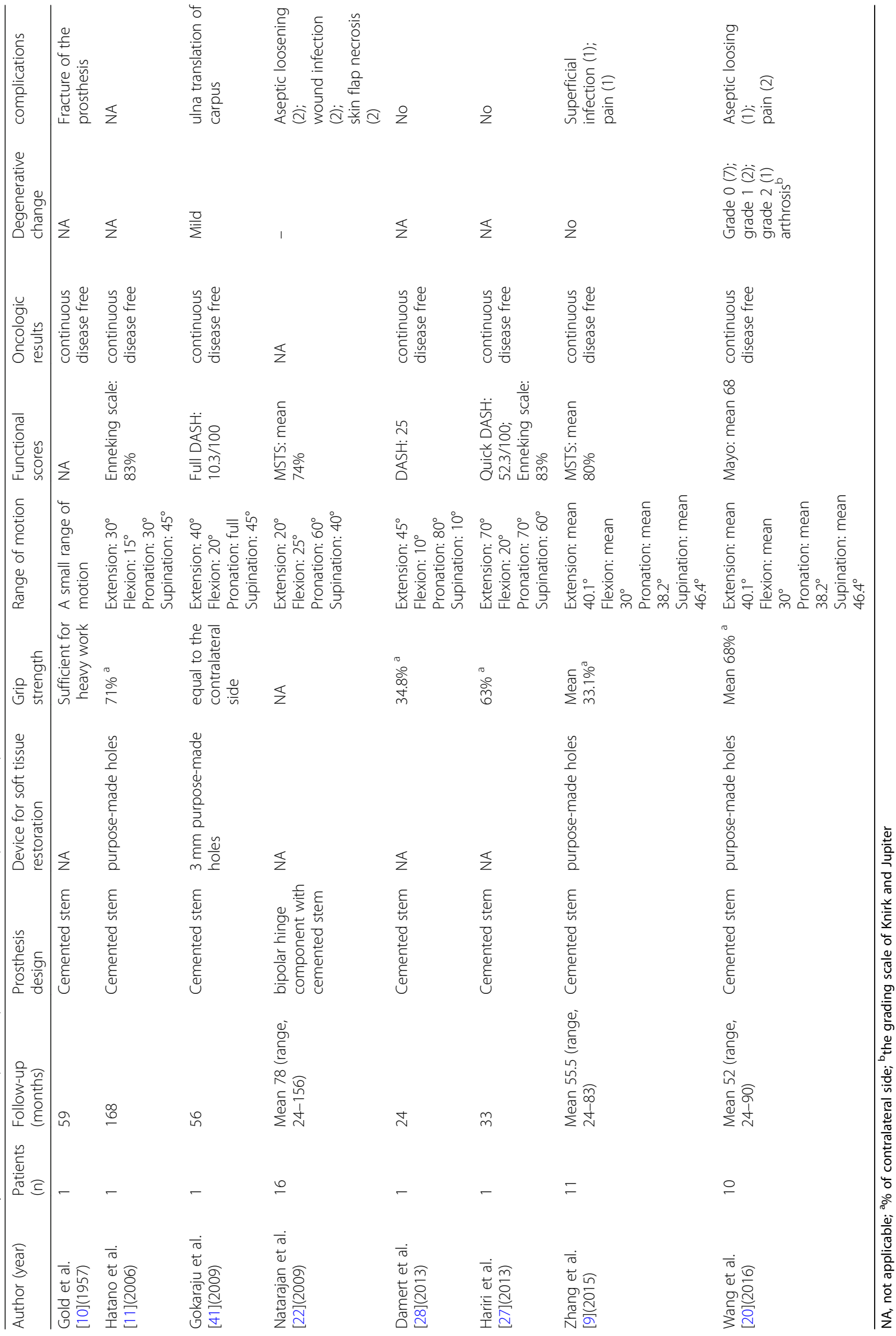



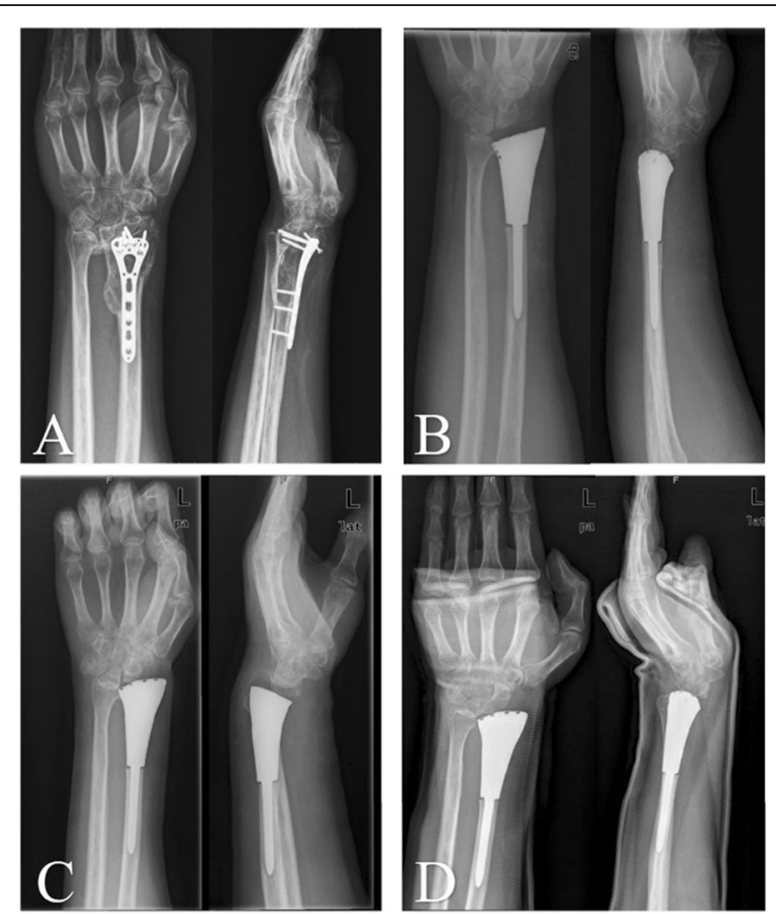

Fig. 8 A: the recurrent GCT was diagnosed in the left distal radius; B: 2 days after prosthetic reconstruction; $\mathbf{C}$ : the palmer subluxation was found in first month after surgery; $\mathbf{D}$ : palmer subluxation was not reduced after four weeks immobilization

control for postoperative dislocation. In addition, considering the relative instability of joint capsule reconstruction, properly delayed rehabilitation is recommended. After osteoarticular allograft reconstruction, wrist degeneration, which has been proven in all patients, severely influence their wrist function compared to the patients with prosthesis reconstruction. Therefore, compared to osteoarticular allograft reconstruction, 3Dprinted prosthesis reconstruction has its irreplaceable advantages at early-stage application, especially in terms of reconstruction of the wrist function, although further study of cases with follow-up is necessary.

\section{Abbreviations}

3D: Three-dimensional; DRUJ: Distal radioulnar joint; GCT: Giant cell tumor; MSTS: Musculoskeletal tumor society; ROM: Range of motion;

TFCC: Triangular fibrocartilage complex

\section{Acknowledgements}

We are thankful for the support of the nurse team from the Department of Orthopedics, West China Hospital. We are thankful for the patients enrolled in this study.

\section{Authors' contributions}

TYW, LM, and CQT were involved with the concept and design of this manuscript. $Y Z, Y L, X Z Y$ and $F T$ were involved with the acquisition of subjects and data. MXL, JW, YQZ, HD, and CQT were involved in the preoperative 3D design. YTW, LM and CQT were involved in postsurgical evaluation of the patients. All authors contributed toward data analysis, drafting and critically revising the paper, gave final approval of the version to be published, and agree to be accountable for all aspects of the work. All authors read and approved the final manuscript.

\section{Funding}

This work was supported, in part, by the National Natural Science

Foundation of China (81702664), Chengdu science and technology project (2017-CY02-00032-GX) and the National Key Research and Development

Program of China (2016YFC1102003).

\section{Availability of data and materials}

The datasets used and analyzed during the current study are available from the corresponding author on reasonable request.

\section{Ethics approval and consent to participate}

This study was approved and monitored by the Ethical Committee of West China Hospital, Sichuan University in China (No.2019117). All patients signed the informed consent.

\section{Consent for publication}

Written informed consent was obtained from all patients for publication of this study and any accompanying images.

\section{Competing interests}

The authors report no competing interest in this work.

Received: 26 October 2019 Accepted: 21 January 2020

Published online: 03 February 2020

\section{References}

1. Szendroi M. Giant-cell tumour of bone. J Bone Joint Surg Br. 2004;86(1):512.

2. Vander Griend RA, Funderburk $\mathrm{CH}$. The treatment of giant-cell tumors of the distal part of the radius. J Bone Joint Surg Am. 1993;75(6):899-908.

3. Abat F, Almenara M, Peiro A, Trullols L, Bague S. Gracia I: [Giant cell tumour of bone: a series of 97 cases with a mean follow-up of 12 years]. Rev Esp Cir Ortop Traumatol. 2015;59(1):59-65.

4. Wysocki RW, Soni E, Virkus WW, Scarborough MT, Leurgans SE, Gitelis S. Is intralesional treatment of giant cell tumor of the distal radius comparable to resection with respect to local control and functional outcome? Clin Orthop Relat Res. 2015;473(2):706-15.

5. O'Donnell RJ, Springfield DS, Motwani HK, Ready JE, Gebhardt MC, Mankin $\mathrm{HJ}$. Recurrence of giant-cell tumors of the long bones after curettage and packing with cement. J Bone Joint Surg Am. 1994;76(12):1827-33.

6. Harness NG, Mankin HJ. Giant-cell tumor of the distal forearm. J Hand Surg. 2004;29(2):188-93.

7. Wang T, Chan CM, Yu F, Li Y, Niu X. Does wrist arthrodesis with structural iliac crest bone graft after wide resection of distal radius Giant cell tumor result in satisfactory function and local control? Clin Orthop Relat Res. 2017; 475(3):767-75

8. McGough RL, Rutledge J, Lewis VO, Lin PP, Yasko AW. Impact severity of local recurrence in giant cell tumor of bone. Clin Orthop Relat Res. 2005; 438:116-22.

9. Zhang $\mathrm{S}, \mathrm{Xu} \mathrm{MT}$, Wang $\mathrm{XQ}$, Wang JJ. Functional outcome of en bloc excision and custom prosthetic replacement for giant cell tumor of the distal radius. J Orthop Sci. 2015;20(6):1090-7.

10. Gold AM. Use of a prosthesis for the distal portion of the radius following resection of a recurrent giant-cell tumor. J Bone Joint Surg Am. 1957;39$A(6): 1374-80$

11. Hatano H, Morita T, Kobayashi H, Otsuka H. A ceramic prosthesis for the treatment of tumours of the distal radius. J Bone Joint Surg Br. 2006;88(12): 1656-8

12. Bianchi G, Donati D, Staals EL, Mercuri M. Osteoarticular allograft reconstruction of the distal radius after bone tumour resection. J Hand Surg (Edinburgh, Scotland). 2005;30(4):369-73.

13. Duan H, Zhang B, Yang HS, Liu YH, Zhang WL, Min L, Tu CQ, Pei FX. Functional outcome of en bloc resection and osteoarticular allograft reconstruction with locking compression plate for giant cell tumor of the distal radius. J Orthop Sci. 2013;18(4):599-604.

14. Szabo RM, Thorson EP, Raskind JR. Allograft replacement with distal radioulnar joint fusion and ulnar osteotomy for treatment of giant cell tumors of the distal radius. J Hand Surg. 1990;15(6):929-33.

15. Seradge $\mathrm{H}$. Distal ulnar translocation in the treatment of giant-cell tumors of the distal end of the radius. J Bone Joint Surg Am. 1982;64(1):67-73. 
16. Pho RWH. Free vascularized fibular transplant for replacement of the lowe radius. J Bone Joint Surg-British Vol. 1979;61(3):362-5.

17. Maruthainar N, Zambakidis C, Harper G, Calder D, Cannon SR, Briggs TWR. Functional outcome following excision of tumours of the distal radius and reconstruction by autologous non-vascularized osteoarticular fibula grafting. J Hand Surg-Brit Eur. 2002;27b(2):171-4.

18. Minami A, Kato H, Iwasaki N. Vascularized fibular graft after excision of giant-cell tumor of the distal radius: wrist arthroplasty versus partial wrist arthrodesis. Plast Reconstr Surg. 2002;110(1):112-7.

19. Szabo RM, Anderson KA, Chen JL. Functional outcome of en bloc excision and osteoarticular allograft replacement with the Sauve-Kapandji procedure for Campanacci grade 3 giant-cell tumor of the distal radius. J Hand Surg. 2006:31(8):1340-8

20. Wang B, Wu Q, Liu J, Chen S, Zhang Z, Shao Z. What are the functional results, complications, and outcomes of using a custom unipolar wrist Hemiarthroplasty for treatment of grade III Giant cell tumors of the distal radius? Clin Orthop Relat Res. 2016;474(12):2583-90.

21. Lu M, Min L, Xiao C, Li Y, Luo Y, Zhou Y, Zhang W, Tu C. Uncemented threedimensional-printed prosthetic replacement for giant cell tumor of distal radius: a new design of prosthesis and surgical techniques. Cancer Manag Res. 2018;10:265-77.

22. Natarajan MV, Chandra Bose J, Viswanath J, Balasubramanian N, Sameer M Custom prosthetic replacement for distal radial tumours. Int Orthop. 2009; 33(4):1081-4.

23. Cooney WP, Linscheid RL, Dobyns JH. Triangular fibrocartilage tears. J Hand Surg. 1994;19(1):143-54.

24. Enneking WF, Dunham W, Gebhardt MC, Malawar M, Pritchard DJ. A system for the functional evaluation of reconstructive procedures after surgical treatment of tumors of the musculoskeletal system. Clin Orthop Relat Res. 1993;286:241-6

25. Knirk JL, Jupiter JB. Intra-articular fractures of the distal end of the radius in young adults. J Bone Joint Surg Am. 1986;68(5):647-59.

26. Henderson ER, O'Connor MI, Ruggieri P, Windhager R, Funovics PT, Gibbons CL, Guo W, Hornicek FJ, Temple HT, Letson GD. Classification of failure of limb salvage after reconstructive surgery for bone tumours : a modified system including biological and expandable reconstructions. Bone Joint J. 2014;96-B(11):1436-40.

27. Hariri A, Facca S, Di Marco A, Liverneaux P. Massive wrist prosthesis for giant cell tumour of the distal radius: a case report with a 3-year follow-up. OTSR. 2013;99(5):635-8

28. Damert HG, Altmann S, Kraus A. Custom-made wrist prosthesis in a patient with giant cell tumor of the distal radius. Arch Orthop Trauma Surg. 2013; 133(5):713-9.

29. Aho AJ, Ekfors T, Dean PB, Aro HT, Ahonen A, Nikkanen V. Incorporation and clinical results of large allografts of the extremities and pelvis. Clin Orthop Relat Res. 1994;307:200-13.

30. Campanacci L, Manfrini M, Colangeli M, Ali N, Mercuri M. Long-term results in children with massive bone osteoarticular allografts of the knee for highgrade osteosarcoma. J Pediatr Orthop. 2010;30(8):919-27.

31. Haugstvedt JR, Langer MF, Berger RA. Distal radioulnar joint: functional anatomy, including pathomechanics. J Hand Surg Eur Vol. 2017;42(4):338-45.

32. Palmer AK, Werner FW. The triangular fibrocartilage complex of the wrist-anatomy and function. J Hand Surg. 1981;6(2):153-62.

33. Rabitsch K, Maurer-Ertl W, Pirker-Fruhauf U, Lovse T, Windhager R, Leithner A. Reconstruction of the distal radius following tumour resection using an Osteoarticular allograft. Sarcoma. 2013;2013:318767.

34. Smith RJ, Mankin HJ. Allograft replacement of distal radius for giant cell tumor. J Hand Surg. 1977;2(4):299-308.

35. Cheng CY, Shih HN, Hsu KY, Hsu RW. Treatment of giant cell tumor of the distal radius. Clin Orthop Relat Res. 2001;383:221-8.

36. Asavamongkolkul A, Waikakul S, Phimolsarnti R, Kiatisevi P. Functional outcome following excision of a tumour and reconstruction of the distal radius. Int Orthop. 2009;33(1):203-9.

37. Li J, Jiao Y, Guo Z, Ji C, Wang Z. Comparison of osteoarticular allograft reconstruction with and without the Sauve-Kapandji procedure following tumour resection in distal radius. J Plast Reconstr Aesthet Surg. 2015;68(7): 995-1002.

38. Bus MP, van de Sande MA, Taminiau AH, Dijkstra PD. Is there still a role for osteoarticular allograft reconstruction in musculoskeletal tumour surgery? A long-term follow-up study of 38 patients and systematic review of the literature. Bone Joint J. 2017;99-B(4):522-30.
39. Ortiz-Cruz E, Gebhardt MC, Jennings LC, Springfield DS, Mankin HJ. The results of transplantation of intercalary allografts after resection of tumors. A long-term follow-up study. J Bone Joint Surg Am. 1997;79(1):97-106.

40. Gold AM. Use of a prosthesis for the distal portion of the radius following resection of a recurrent Giant-cell tumor. J Bone Joint Surg Am. 1965;47: 216-8.

41. Gokaraju K, Sri-Ram K, Donaldson J, Parratt MT, Blunn GW, Cannon SR, Briggs TW. Use of a distal radius endoprosthesis following resection of a bone tumour: a case report. Sarcoma. 2009;2009:938295.

42. Campanacci M, Baldini N, Boriani S, Sudanese A. Giant-cell tumor of bone. J Bone Joint Surg Am. 1987:69(1):106-14.

43. Branstetter DG, Nelson SD, Manivel JC, Blay JY, Chawla S, Thomas DM, Jun S, Jacobs I. Denosumab induces tumor reduction and bone formation in patients with giant-cell tumor of bone. Clin Cancer Res. 2012;18(16):4415-24.

44. Jamshidi K, Gharehdaghi M, Hajialiloo SS, Mirkazemi M, Ghaffarzadehgan K, Izanloo A. Denosumab in patients with Giant cell tumor and its recurrence: a systematic review. Arch Bone Jt Surg. 2018;6(4):260-8.

45. Tsukamoto S, Righi A, Vanel D, Honoki K, Donati DM, Errani C. Development of high-grade osteosarcoma in a patient with recurrent giant cell tumor of the ischium while receiving treatment with denosumab. Jpn J Clin Oncol. 2017:47(11):1090-6.

\section{Publisher's Note}

Springer Nature remains neutral with regard to jurisdictional claims in published maps and institutional affiliations.
Ready to submit your research? Choose BMC and benefit from:

- fast, convenient online submission

- thorough peer review by experienced researchers in your field

- rapid publication on acceptance

- support for research data, including large and complex data types

- gold Open Access which fosters wider collaboration and increased citations

- maximum visibility for your research: over $100 \mathrm{M}$ website views per year

At BMC, research is always in progress.

Learn more biomedcentral.com/submissions 